\title{
CORRESPONDENCE
}

\section{DDT and Pelicans}

SIR,-Nature $(\mathbf{2 4 0}, 248 ; 1972)$ reports Dr Robert Risebrough's allegation that reproductive failure of the brown pelican in 1969-72 on Anacapa Island was due to DDT pollution "from a Los Angeles factory which in 1970 was discharging 500-1,000 lb of DDT daily into the sea".

This is a charge that Dr Risebrough has been making against Montrose, the factory he is referring to, for the last two years. I have sent letters to a California legislative committee and to Dr Risebrough himself outlining Montrose's treatment of its effluent since its start of manufacture more than 25 years ago. We have always settled DDT effluents in a settling pond, hauling the DDT sediments to a dump that accepts such wastes once or twice a year. The effluent to the county sewer line has contained entrained DDT equivalent to about $10-15$ pounds per day. In May 1971, Montrose achieved essentially total recycle of its wastes and its discharge is about $1 \mathrm{oz}$ of DDT per day.

The discovery of brown pelican reproductive failure was made shortly after the large oil-spill at Anacapa in 1969. W. Hazeltine (Nature, 239, 410; 1972) and Switzer and Wolfe (Nature, 240,$162 ; 1972$ ) point out the invalidity of the attempted correlation of DDE residues and eggshell thinning.

At recent Washington DC DDT hearings, cross-examination of Dr Risebrough and others who hold to this correlation theory clearly demonstrated that without exception they used unreliable statistical approaches. Others, who have applied valid statistical analysis, such as Switzer for terns, demonstrated no such correlation.

Dr Risebrough's charges are becoming entrenched in the scientific literature. When such charges are referenced often enough, they become irrefutable "facts". I would hope that Nature will not allow itself to become part of this process.

Yours faithfully, MaX Sobelman

Montrose Chemical Corporation, Torrance, California 90507

\section{Creation in California}

SIR,- - Although I hesitate to claim to be an expert "in a field of science bearing on the evolutionary theme", and therefore have not been able to take up your offer (Nature, 239, 420; 1972), I have recently been involved in teaching and research on chemical taxonomy, and this has enabled me to look afresh at the subject of evolution. This has been done against a background of work on biogenesis which has certain similarities to evolution, for in it an attempt is made to determine how simple molecules have evolved into more complex ones during the life of the plant. Fifty years ago phytochemists speculated on possible pathways of biogenesis, some most fruitfully, but no one accepted these ideas as fact (or "truth") till innumerable experiments, checking and rechecking claims, have established some pathways with reasonable certainty. Looking therefore afresh at evolution, the most striking feature I find is the highly speculative nature of the topic; the situation phytochemists (in their obviously much more limited sphere of interest) were in 50 years ago.

For instance, one would have expected that classification of plants and animals would have been one of the first subjects to benefit from Darwin's ideas, as here at last was the basis for a "natural classification". Some modern plant taxonomists do not agree and feel that nothing has been fundamentally effected. "What is the impact of Darwin's ideas on taxonomy? It is commonly stated, or implied, that they were revolutionary. No taxonomist who has ever given a moment's thought to what he is doing in comparison to his predecessors can believe this. He knows that taxonomy in its broad outlines and in its more detailed practice has hardly been affected by evolutionary ideas. There is a curious dishonesty about this in much biological writing. Either the fact is denied, or it is glossed over, as if it is something to be ashamed of"1. In fact some seem to suggest that evolutionary ideas have been a hindrance to taxonomy. "In the absence of complete fossil records, so-called 'phylogony' is deduced from taxonomy. Attempts to base taxonomy on 'phylogenetic criteria' generally involve circular arguments, and it is now belatedly coming to be realized that evolutionary speculation has had a deleterious effect on practical taxonomy"2. I find it difficult therefore to accept your opinion that "Darwinism occupies a place in science at least as strong as that of Newton's Laws".

Clearly, the situation is no fault of the biologists; if adequate facts are not available they have to do with what they have. But it amazes me why biologists seem wedded to the rather limiting assumption that God must have created life only once. Could $\mathrm{He}$ not have repeated the operation, on various scales of complexity, several times, thus explaining the great gaps between phyla and such insoluble problems as the origin of the angiosperms? I should guess that one of the motives behind the "Californian Creationists" is to ensure that young people are aware that the Bible, inter alia, at least suggests this possibility. Like many of the people referred to by Dr Hayward ${ }^{3}$ I treat the Genesis account of creation with as much respect as that of the biologist. Perhaps we are not too far removed from Darwin, who ended his Origin of Species with these words: "There is a grandeur in this view of life, with its several powers, having been originally breathed by the Creator into a few forms or into one whilst this planet has gone cycling on according to the fixed law of gravity...." Yours faithfully,

J. W. FAIRBAIRN

The School of Pharmacy,

University of London,

29/39 Brunswick Square,

London WC1N $1 A X$

1 Walton, S. M., in Chemical Plant Taxonomy (edit. by Swain, T.), 6 (Academic Press, London and New York, 1963).

2 Watson, L., Williams, W. T., and Lance, G. N., J. Linn. Soc., 59, 492 (1966).

3 Hayward, A. T. J., Nature, 240, 577 (1972)

\section{Doctrine of Creation}

SIR, - The argument as between the theory of evolution in general and Darwin's theory of natural selection in particular on the one hand, and the account of the creation in the book of Genesis on the other, is surely of no religious interest. But that such an argument should exist is of profound significance for science.

All scientists know that it is not the purpose of science to arrive at ultimate truth. Science is nothing more than a systematic description of phenomena by means of "theories", commonly expressed in the form of "laws". None of these theories and laws is sacrosanct; all are provisional.

As a small boy, early in the century, I was brought up in an old-fashioned school. We were taught that the biblical story of the creation and the subsequent events in the garden of Eden was an allegory. The allegorical truth of that story still remains unshaken. That is so in spite of the fact that I sometimes feel I can detect certain ideological overtones in the writing.

That scientists should still be arguing 